\title{
As intervenções com autores de violência doméstica e familiar no Brasil e suas relações com a Lei Maria da Penha*
}

\author{
Raíssa Jeanine Nothaft** \\ Teresa Kleba Lisboa***
}

Resumo

Neste artigo buscamos analisar as relações entre as intervenções que tem como destinatários de suas ações os autores de violência e a Lei Maria da Penha. Para tanto, nos aprofundaremos nas Recomendaçôes Gerais e Diretrizes editadas pela Secretaria de Políticas para mulheres em 2008. As análises - desenvolvidas tendo como base a literatura especializada, relatórios e pesquisas existentes sobre o tema - ressaltam que a promulgação da Lei Maria da Penha ao mesmo tempo que trouxe previsão legal e ampliação da discussão sobre as intervenções, criou alguns desafios para as iniciativas anteriores a ela, estruturadas em outro contexto legal e político.

Palavras-chave: Violência de Gênero, Violência Doméstica e Familiar, Lei Maria da Penha, Autores de Violência, Políticas Públicas.

\footnotetext{
* Recebido em 29 de maio de 2018, aceito em 27 de julho de 2020. Essa discussão compõe a pesquisa doutoral da primeira autora, intitulada Experiências de mulheres no enfrentamento à violência doméstica e familiar e suas relações com os serviços para autores de violência, orientada pela coautora. O presente trabalho foi realizado com apoio da Coordenação de Aperfeiçoamento de Pessoal de Nível Superior (CAPES), Código de Financiamento 001.

** Doutora em Ciências Humanas pela Universidade Federal de Santa Catarina (UFSC), integrante do NUSSERGE/UFSC e Margens/UFSC, Florianópolis, SC, Brasil. raissajnothaft@gmail.com/ https://orcid.org/0000-00023933-0379

*** Professora Titular Aposentada da Universidade Federal de Santa Catarina; coordenadora do Instituto de Estudos de Gênero da UFSC e integrante do Núcleo Interdisciplinar de Estudos em Saúde Sexualidade e Relações de Gênero (NUSSERGE/UFSC), Florianópolis, SC, Brasil. tkleba@gmail.com / https://orcid.org/0000-0001-8328-7630
} 
Interventions with Perpetrators of Domestic and Family Violence in Brazil and Their Relations with the Maria da Penha Law

\section{Abstract}

This article analyzes relationships between interventions with perpetrators of domestic and family violence and Brazil's Maria da Penha Law. It examines the General Recommendations and Guidelines drafted by the Secretariat for Women's Policies in 2008. The analyses, based on specialized literature, reports and research on the subject, emphasize that while enactment of the Maria da Penha Law provided a legal framework and broadening of the discussion on the subject, it also created challenges for earlier initiatives, which were structured in another legal and political context.

Keywords: Gender Violence, Domestic and Family Violence, Maria da Penha Law, Perpetrators of Violence, Public Policies. 
A violência doméstica e familiar permanece como uma relevante fonte de exclusão social. Até pouco mais de uma década, a maioria dos países tendia a negligenciar a existência desse problema. Contudo, hoje existe tratamento legal em um número crescente de países, o que facilita a criação de políticas públicas, a intervenção do Estado e da sociedade civil nessas situações.

Ao mesmo tempo, pesquisas ao redor do mundo têm ressaltado a necessidade de trabalhar com os autores de violência, e envolvê-los nas políticas de prevenção de novas violências (Flood, 2011; Antezana, 2012). Nesse contexto, as intervenções com homens autores de violência têm se destacado como ações que, aliadas às dirigidas às mulheres, podem constituir-se enquanto novas possibilidades no enfrentamento à violência doméstica e familiar (Toneli, 2007; Lima; Buchelle, 2011), dado que só conseguiremos trabalhar no campo da prevenção se mudarmos atitudes, identidades e relações que encorajam violência (Soares, 2012; Flood, 2011; Geldschläger, Ginés, Ponce, 2011).

Existem diversas nomenclaturas para o que chamamos aqui de "intervenções com autores de violência doméstica e familiar". Utilizamos essa expressão de forma a abranger práticas interventivas desenvolvidas em variados formatos para combater essas situações de violência a partir do trabalho com seus autores. São desenvolvidas com pessoas encaminhadas via decisão judicial ou a partir de demanda espontânea - pelo conhecimento do serviço e solicitação das companheiras, ou do encaminhamento pela rede de atendimento às mulheres em situação de violência, serviços de saúde, conselho tutelar, entre outros. As iniciativas brasileiras são mais frequentemente chamadas de Programas, Serviços, Núcleos, Grupos de reflexão ou Grupos reflexivos, sendo que as duas últimas expressões também definem o formato da política. Para efeito desse artigo, os termos "intervenções" e "políticas" serão utilizados como sinônimos para abranger todas essas possibilidades.

No âmbito internacional, as intervenções com homens autores de violência já têm uma história de pelo menos quarenta anos. A primeira tentativa internacional de identificar e descrever políticas para autores de violência foi o Relatório "Intervining with Perpetrators of Intimate Partner Violence: a Global Perspective" lançado em 2003 pela Organização Mundial da Saúde (OMS). Essas intervenções, em sua maioria, apresentavam "como elemento principal da violência a diferença de poder entre homens e mulheres e, como orientação teórica, as perspectivas feministas de gênero" (Mistura; Andrade, 2017:243).

No Brasil, esse é um eixo de abordagem relativamente recente, principalmente no que se refere às estratégias de políticas públicas. Entre as iniciativas documentadas, as pioneiras são da Ong Pró-Mulher, Família e Cidadania (São Paulo) e do Instituto Noos (Rio de Janeiro), ambos nos anos 1990. A construção dessas iniciativas teve percursos distintos. A primeira desenvolvia mediação familiar em casos julgados no âmbito da Lei 9099/95 e em 1993 passou a oferecer grupos de reflexão com mulheres em situação de violência $e$ homens envolvidos nas denúncias (Muszkat, 2006; Lima; Büchele, 2011; Cepia, 2016).

O Instituto Noos, inicialmente não tinha relação com a violência doméstica, mas com a demanda de homens em terapia, dando origem a grupos de reflexão sobre masculinidades. A metodologia ${ }^{1}$ do Instituto Noos foi construída a partir de grupos de gênero realizados com homens de diversos contextos, faixas etárias, etnias e camadas sociais da população da cidade do Rio de Janeiro, dentre eles: "estudantes da rede pública e privada, policiais militares, moradores, líderes e agentes sociais de comunidades empobrecidas, universitários, profissionais de nível superior e autores de violência doméstica e de gênero" (Acosta; Andrade Filho; Bronz, 2004:12). No final dos anos 1990, essa metodologia passou a ser utilizada com autores de violência doméstica e familiar num projeto com a Subsecretaria de Pesquisa e Cidadania da Secretaria de Segurança Pública do Estado do Rio de Janeiro. Outras intervenções precursoras foram o Núcleo de Atendimento à Família e aos Autores de Violência Doméstica (NAFAVD), que teve seu projeto piloto criado em 2003 na região administrativa de Samambaia/DF; o Programa de Prevenção e Combate à Violência Doméstica e Intrafamiliar (PPVCDI) da Prefeitura de Blumenau/SC, que iniciou as intervenções com

\footnotetext{
1 Para saber mais sobre a metodologia do Instituto Noos, ver as publicações: Acosta; Andrade Filho; Bronz(2004) e Beiras; Bronz(2016).
} 
homens em 2004 e o Programa Albam, ONG de Belo Horizonte, que começou suas intervenções em 2005 (Aguiar, 2009; Beiras, 2014).

Nesse artigo, buscamos analisar as intervenções em âmbito nacional e suas relações com a Lei Maria da Penha. Esse enfoque principal se desdobra em um segundo, que são as Recomendaçóes Gerais e Diretrizes da Secretaria de Políticas para as Mulheres do Governo Federal para a implementação dos serviços de responsabilização e educação dos agressores, editadas pela Secretaria de Políticas para as Mulheres em 2008. Esse estudo se faz necessário tendo em vista que a Lei Maria da Penha trouxe amparo legal para essas intervenções, e as Recomendações consolida aspectos mínimos a serem seguidos em âmbito nacional. Ambas as análises se darão a partir da literatura especializada, relatórios e pesquisas existentes sobre o tema no Brasil. O artigo está dividido em duas partes, onde desenvolvemos cada um desses enfoques, além dessa introdução e considerações finais.

\section{As intervenções para autores de violência no Brasil: histórico e suas relações com a Lei Maria da Penha}

As primeiras intervenções com autores de violência no Brasil fizeram parte de um movimento que buscava politizar o enfrentamento à violência doméstica e familiar considerada, naquele momento, infração de menor potencial ofensivo, de acordo com a Lei 9.099/95. Essa Lei, que surgiu no intuito de desafogar o Poder Judiciário, criou os Juizados Especiais Criminais (JECRIMs) para processar crimes com pena privativa de liberdade de até um ano, por ela definidos como crimes de menor potencial ofensivo. Os Juizados operavam principalmente a partir de formas alternativas de resolução de conflitos, como a conciliação, transação penal e suspensão condicional do processo. O propósito da Lei não era tratar especificamente da violência doméstica, apesar disso, "estima-se que cerca de $60 \%$ dos crimes que chegavam aos Juizados Especiais Criminais JECRIMs eram de lesão corporal leve e ameaça, cometidos em relações conjugais" (Soares, 2018:18). Segundo Sinhoretto e Tonche (2019), os estudos sobre os impactos das inovações trazidas pela Lei 9.009 de 1995 aos casos de violência doméstica apontaram aumento no acesso à justiça e na publicização dos conflitos domésticos, tendo em vista que o número de casos reportados aumentou. Algumas autoras também creditam à Lei um aumento do protagonismo das mulheres, devido ao uso de formas alternativas de administração de conflitos e possibilidade de discutir reparação de danos e subverter as relações de poder (Izumino, 2002). Por outro lado, conforme os anos foram passando, os Juizados foram perdendo sua celeridade inicial e se burocratizando. Os juízes e os promotores, ao adotar modelos e padronizar sua atuação nos casos, transformaram os juizados em "uma espécie de linha de montagem" (Batitucci et al, 2010).

A burocratização

[...] terminou por sufocar a capacidade dos juizados em ser um espaço equilibrado de negociação dos interesses das vítimas. Em parte, isto foi atribuído à mentalidade conservadora dos operadores jurídicos, que passaram a aplicar penas consideradas inócuas ou ineficientes para a reeducação dos agressores (Sinhoretto; Tonche, 2019:3).

Essas penas eram majoritariamente multas ou pagamento de cestas básicas (Segato, 2003). Além das penas alternativas, outro instituto criticado era a conciliação. Segundo Lima e Büchele (2013:20), sua centralidade nos Juizados e "o despreparo de parte dos operadores do Direito conduzia ao alto número de conciliações indesejadas (ou coagidas) e ao arquivamento de processos". A aplicação desse instituto, centrada nos princípios da informalidade e celeridade, agia em prol da preservação da família, reificando as relações violentas e desqualificando os seus impactos na vida das mulheres (Santos, 2010). Essa aplicação da Lei 9.099/95 levou correntes do movimento de mulheres a reivindicar a prisão como "a única punição adequada aos conflitos de gênero, fazendo eco a um movimento de endurecimento penal que se intensificou no Brasil" (Sinhoretto; Tonche, 2019:3).

Nesse contexto, as primeiras intervenções com homens autores de violência foram pensadas como alternativas ao encarceramento $e$ às penas pecuniárias, e como medidas que poderiam gerar transformações nas relações de poder e violências delas decorrentes. Contudo, não foram recebidas 
sem resistência pelos juízes responsáveis pelos casos, ainda imersos em uma lógica de privatização dos conflitos domésticos e sem capacitação para lidar com esses tipos de violência (Soares, 2004).

A Lei 11.340 de 2006 trouxe uma legitimidade antes inexistente às intervenções (Toneli, 2007; Lima, 2008; Nothaft, 2016), amparando-as legalmente nos artigos 35 e 45, que preveem a criação de "centros de educação e de reabilitação para os agressores" e "o comparecimento obrigatório do agressor a programas de recuperação e reeducação" (Brasil, 2006), respectivamente. Essa Lei, nomeada Lei Maria da Penha em homenagem à Maria da Penha Fernandes - brasileira que obteve a condenação ${ }^{2}$ do Estado brasileiro na Comissão Interamericana de Direitos Humanos pelo descaso do judiciário no julgamento das duas tentativas de assassinato que sofreu de seu marido e a deixaram paraplégica - representa a consolidação de mais de 30 anos de lutas dos movimentos feministas e de mulheres.

A criação da Lei decorreu de um longo processo de discussão nacional, que envolveu a formação de um Consórcio de organizações feministas em 2002 para elaboração de uma proposta de anteprojeto e muita pressão ao governo para sua promulgação. Ela reflete uma articulação estreita entre o governo e os movimentos feministas e de mulheres no reconhecimento da violência doméstica e familiar como um problema de políticas públicas (Prá, 2010; Santos, 2010; Lisboa, 2014; Pasinato, 2015). Sua abrangência a torna uma política ampla de enfrentamento à violência, exigindo, para sua implementação, a articulação dos três poderes - Executivo, Judiciário e Legislativo - nos três níveis de governo federal, estadual e municipal.

A Lei Maria da Penha rompe com uma visão meramente punitivista e incorpora perspectivas de prevenção e proteção (Lisboa, 2010; Campos, 2015). No entanto,

quer no domínio da formulação/adoção, quer no da implementação, ocorrem variadas formas de absorção/tradução que restringem $e$ ampliam, transformam e traem os significados $e$ os escopos imprimidos pelas feministas aos textos legais e às políticas públicas (Santos, 2010:167),

e o caso dessa lei não é diferente. Pesquisas nos últimos quatorze anos vêm ressaltando os inúmeros obstáculos para a sua plena implementação e efetivação, como a resistência dos operadores do direito (Santos, 2010; Campos, 2015; Pasinato, 2015), a insuficiência da rede especializada de serviços e a falta de investimento para sua criação e manutenção (Campos, 2015), a baixa especialização dos profissionais e a permanência de atendimentos discriminatórios $e$ prejudiciais às mulheres (Pasinato, 2015), entre outros. Circunstâncias que resultam na

[...] não universalização do acesso à justiça $e$ em direitos para mulheres que terminam, muitas vezes, com um boletim de ocorrência em uma das mãos e uma medida de proteção na outra, sem que, para além desses papéis, existam políticas que deem mais efetividade à sua proteção $e$ condições para que saiam da situação de violência (Pasinato, 2015:535).

Cabe ressaltar que o próprio texto legal, apesar de seus avanços, apresenta limitações ao excluir as manifestações de violência de gênero em espaços públicos não perpetradas por familiares (Pazo, 2013). Essas violências são muito comuns no Brasil e estão fora do escopo de qualquer legislação preventiva, protetiva e punitiva, como os casos de assédio que não configuram estupro, por exemplo. A escolha por esse enquadramento,

[...] ao invés de violência de gênero, como é definida na Espanha por exemplo, foi uma decisão política com o objetivo de dar maior visibilidade a esse fenômeno específico. Com essa escolha, exclui-se uma discussão mais ampla sobre a questão de gênero pois um enquadramento mais flexível resultaria na possibilidade de inclusão de outros grupos lesados, como, por exemplo, as vítimas de crimes homofóbicos (Amado, 2017:234).

\footnotetext{
2 Mais informações sobre o caso e a condenação do Estado brasileiro podem ser encontradas no Relatório N. 54/01 da Comissão Interamericana de Direitos Humanos [http://www.sbdp.org.br/arquivos/material/299 Relat\%20n.pdf - acesso em: out. 2019].
} 
Além de seu escopo reduzido, a Lei Maria da Penha protege apenas as pessoas dentro do guarda-chuva identitário mulher. Esse fato exclui os homens trans e pessoas não binárias ${ }^{3}$, que, muitas vezes, sofrem violências dentro de suas próprias casas e/ou cometidas por familiares devido a não aceitação de suas identidades de gênero. Isso no país que mais mata LGBTTQIs no mundo e não possui nenhuma legislação protetiva ou que declare seus direitos ${ }^{4}$. E traz um tratamento jurídico e acesso a políticas públicas diferenciado para as violências domésticas e familiares sofridas por meninas e meninos no âmbito de uma mesma família.

Desde as primeiras iniciativas até os dias atuais, as intervenções estão muito mais difundidas. Após a criação da Lei Maria da Penha cresceu, principalmente, o número de intervenções governamentais (Toneli; Beiras; Ried, 2017). Em 2014, o Relatório Mapeamento de Serviços de atenção grupal a homens autores de violência contra mulheres no contexto brasileiro mapeou 25 programas em diferentes estados brasileiros, obtendo informações mais detalhadas sobre 19 deles. Esse relatório, publicado pelo Instituto Noos, foi o primeiro mapeamento que buscou conhecer, de forma exploratória e descritiva, as experiências nacionais de serviços de atenção a homens autores de violência doméstica e familiar. Em 2019, o Núcleo Margens em parceria com o Instituto Noos publicou uma ampliação dessa pesquisa onde identificou pelo menos 41 iniciativas em todo país (Beiras; Nascimento; Incrocci, 2019).

Em 2016, a organização não governamental Cidadania, Estudo, Pesquisa, Informação e Ação (CEPIA) publicou o Relatório de Pesquisa Violência contra as mulheres: os serviços de responsabilização dos homens autores de violência. Esse relatório mapeou os serviços existentes nas capitais brasileiras. Das $27^{5}$ capitais, apenas em 14 foi verificado a existência de iniciativa vigente direcionada para autores de violência: Belém, Belo Horizonte, Distrito Federal, Natal, Porto Alegre, Porto Velho, Rio de Janeiro, São Luís, São Paulo e Vitória. Em Maceió, Salvador, Palmas e Aracaju as iniciativas são fruto de parcerias com universidades públicas e estão em fase de implementação (Cepia, 2016).

Em 2018, o IBGE lançou a Pesquisa de Informações Básicas Municipais ${ }^{6}$ - MUNIC com um de seus capítulos destinados às Políticas para mulheres. No levantamento da quantidade de municípios com serviços especializados de enfrentamento à violência contra mulheres, um tipo pesquisado foi: Serviço de Responsabilização do Agressor. Essa política foi encontrada em 113 municípios brasileiros, distribuídos em todas as regiões. Os estados em que não foram encontrados serviços em desenvolvimento foram Roraima, Alagoas e Tocantins (IBGE, 2019). Se comparamos esses dados com o número de municípios brasileiros, menos de $3 \%$ deles contaram com esse tipo de política em 2018.

Cruzando as informações dos três relatórios com os dados da MUNIC (IBGE, 2019), as teses e dissertações analisadas em pesquisa anterior (Nothaft, 2016), e pesquisa exploratória (Nothaft, 2020; Martins, 2020) é possível afirmar que, ao menos, 157 cidades brasileiras já tiveram alguma

\footnotetext{
${ }^{3}$ Apesar de não haver recenseamento governamental da população trans e travesti, as autoras do Dossiê dos assassinatos e da violência contra travestis e transexuais no Brasil trabalham com a estimativa de que $1,9 \%$ da população mundial seja não-cisgênera, "sendo $1,1 \%$ da população pertencente ao gênero feminino (travestis e mulheres transexuais); e $0,8 \%$ pertencentes ao gênero masculino (homens trans e transmasculinos)" (Benevides; Nogueira, 2020:28) ou seja, deixa sem proteção mais de 1,7 milhões de pessoas no Brasil.

4 Em 13 de junho de 2019, o Supremo Tribunal Federal (STF) determinou que discriminação por orientação sexual e identidade de gênero é crime no Brasil, a ser punido de acordo com a Lei de Racismo (7716/89). Essa decisão foi questionada pelos movimentos sociais e intelectuais críticos ao sistema penal por seu caráter punitivo prisional, que reforça o encarceramento em massa da população negra e pobre. Além disso, não protege a população LGBTTQI+ mais vulnerável, que são as mulheres trans e travestis negras trabalhadoras sexuais, frequentemente alvo da hostilidade policial e da seletividade penal (Benevides; Nogueira, 2020).

${ }^{5}$ Em 6 capitais não foram identificadas iniciativas: Macapá (AP), Boa Vista (RR), João Pessoa (PB), Teresina (PI), Goiânia (GO) e Campo Grande (MS); em 3 capitais não houve retorno das instituições - Cuiabá (MT), Curitiba (PR) e Florianópolis (SC); e em 4 capitais as iniciativas foram extintas: Rio Branco (AC), Manaus (AM), Fortaleza (CE) e Recife (PE).

6 "Trata-se, basicamente, de um levantamento pormenorizado de informações sobre a estrutura, a dinâmica e o funcionamento das instituições públicas municipais, em especial a prefeitura, compreendendo, também, diferentes políticas e setores que envolvem o governo municipal" (IBGE, 2019:9).
} 
experiência de intervenção com autores de violência doméstica e familiar. Em uma perspectiva cronológica,

[...] percebemos um grande avanço na implementação de serviços para autores de violência doméstica e familiar nos últimos 6 anos, quando o primeiro mapeamento foi feito, contudo essa quantidade de iniciativas está muito aquém da necessidade do Brasil, dadas suas proporções territoriais. Dentre os estados brasileiros, apenas em Roraima não foram documentadas atividades (Nothaft, 2020:35).

As políticas neste setor ainda são muito frágeis, tornando necessárias mais pesquisas, discussões e execução de intervenções nacionalmente (Toneli; Beiras; Ried, 2017). Há, em alguns países, instrumentos que regulam e determinam aspectos mínimos que deveriam ser seguidos ${ }^{7}$. Coincidem, entre outros aspectos, na necessidade de trabalhar com perspectiva feminista de gênero e masculinidades, em rede com outras políticas de enfrentamento à violência doméstica e familiar; de formação continuada para os facilitadores dos programas; e de processos de avaliação $e$ controle, de modo a garantir seu funcionamento e estabelecer resultados (Beiras; Nascimento; Incrocci, 2019). No Brasil, as principais diretrizes estatais ${ }^{8}$ são as Recomendaçôes Gerais e Diretrizes da Secretaria de Políticas para as Mulheres do Governo Federal para a implementação dos serviços de responsabilização e educação dos agressores. Devido sua importância no contexto nacional, nos deteremos em sua análise no próximo item.

Recomendações Gerais e Diretrizes da Secretaria de Políticas para as Mulheres do Governo Federal para a implementação dos serviços de responsabilização e educação dos agressores

\section{Esse documento}

[...] constitui o resultado de discussões realizadas por diferentes Ministérios e representantes da sociedade civil no workshop Discutindo os Centros de Educação e Reabilitação do Agressor", realizado no Rio de Janeiro em julho de 2008 (Brasil, 2008:1).

As Recomendações e Diretrizes, editadas pela Secretaria de Políticas para as Mulheres em 2008, visam apresentar conceitos, atribuições e objetivos desses serviços à luz da Lei 11.340/2006, conforme previsto nos artigos 35 e 45. O texto da Lei prevê centros/ programas d e educação/recuperação e reabilitação/reeducação de agressores. Essas diferentes denominações implicam em diferentes objetivos, metodologias e perspectivas teórico-epistemológicas.

Nas Recomendações foi mantido apenas o termo educação, sendo recuperação, reabilitação e reeducação substituídos por responsabilização. Na sua construção, optou-se pela nomenclatura "serviço", para diferenciá-los das políticas assistenciais destinadas às mulheres em situação de violência, nomeadas "centros" - conforme previsto no art. 35. Refere-se, ainda, genericamente ao autor de violência como "agressor", mesma designação da Lei. Existe uma vasta problematização frente ao uso dessa palavra, uma vez que ela designa uma identidade e reitera a ideia de que o "lócus da violência são os próprios homens" (Soares, 2012:202). Seu uso na Lei e nas Recomendações contraria inclusive o discurso de legislações penais, como o Código Penal, que utiliza o termo "agente", na maioria de seus artigos, para nomear o autor do fato. Palavras como agressor ou criminoso reportam a uma lógica essencialista e subentendem a imutabilidade de condutas, independentemente do trabalho desenvolvido. Seu uso contradiz inclusive os objetivos dos serviços, conforme previsto nas Recomendações. "Autor de violência", por outro lado, remete a

\footnotetext{
7 Ver Monteiro, Andrés; Bonino, Luis. (2006); WWP (2008); Híjar, M.; Valdéz-Santiago, R. (2010).

8 Existe ainda o Manual de Gestão para alternativas penais: medidas protetivas de urgência e demais serviços de responsabilização para homens autores de violências contra as mulheres, produto de uma Consultoria Nacional Especializada para Formulação de Modelo de Gestão para as Alternativas Penais, projeto BRA/011/2014 - Fortalecimento da Gestão do Sistema Prisional Brasileiro, parceria entre Departamento Penitenciário Nacional e o Programa das Nações Unidas para o Desenvolvimento, lançado em 2016. No âmbito dos estados, há também o documento elaborado pela Coordenadoria Estadual da Mulher em Situação de Violência Doméstica e Familiar do Tribunal de Justiça do Rio de Janeiro (Cepia, 2016).
} 
alguém que praticou ou pratica violência. Assim, evidencia a violência enquanto prática social e, consequentemente, passível de ser transformada a partir de processos reflexivos sobre relações de poder $e$ masculinidades.

O serviço deve ter caráter obrigatório e pedagógico com base em uma perspectiva feminista de gênero, e não de 'tratamento' (seja psicológico, social ou jurídico). Ou seja, descarta fatores como alcoolismo, uso de drogas e desemprego como causadores do problema. E objetiva

[...] a conscientização dos agressores sobre a violência de gênero como uma violação dos direitos humanos das mulheres e para a responsabilização desses pela violência cometida. Juntamente com demais atividades preventivas - tais como realização de campanhas nacionais e locais, formação de professores e inclusão das questões de gênero e raça nos currículos escolares - o serviço poderá contribuir para a desconstrução de estereótipos de gênero; a transformação da masculinidade hegemônica; e a construção de novas masculinidades (Brasil, 2008:2).

Antezana (2012), ao refletir sobre os pressupostos teóricos tácitos programas de intervenção para homens autores de violência, em âmbito internacional, enumera quatro principais modelos ou enfoques: psicopatológico - distúrbios da personalidade: "este enfoque, desenvolvido por psicólogos, considera que os homens que praticam violência repetidamente são portadores de distúrbios da personalidade" (Antezana, 2012:12), explica, assim, a violência de forma individual sem levar em consideração seu contexto sociocultural; psicoeducativo pró-feminista - "propõe uma leitura de gênero sobre a violência, reposicionando o problema como uma questão tipicamente social, mais do que individual" (Antezana, 2012:13), ou seja, no âmbito das relações de poder entre homens e mulheres. À essa leitura se soma a filosofia educativa de Paulo Freire, que considera as pessoas capazes de questionar de maneira crítica suas realidades e, a partir da reflexão, modificar a si mesmo; cognitivo-comportamental - esse enfoque considera a violência apenas no nível individual e concentra-se em modificar, mediante técnicas de reestruturação cognitiva e controle da ira, "as concepções incorretas da realidade, que se traduzem em déficits no autocontrole das emoções ou em baixas capacidades de negociação ou solução de conflitos" (Antezana, 2011:14); construtivista-narrativista com perspectiva de gênero (CNPG) - considera, ao mesmo tempo, o contexto sociocultural e político próprio dos enfoques pró-feministas e das teorias de gênero e as colaborações psicoterapêuticas, buscando assim estabelecer um "diálogo com os homens no que diz respeito às suas próprias experiências, vivências, sentimentos, significados e intenções" (Antezana, 2011:15).

As Recomendações consideram a violência doméstica e familiar como um fenômeno social que se funda em desigualdade de poder. $\mathrm{E}$ os serviços são pensados para contribuir com "a responsabilização dos homens pela violência cometida e para a desconstrução de estereótipos de gênero e de padrões hegemônicos de masculinidade", e "devem buscar o questionamento das relações de gênero que têm legitimado as desigualdades sociais e a violência contra as mulheres, por meio de atividades educativas, reflexivas e pedagógicas vinculadas à responsabilização dos agressores" (Brasil, 2008:3). Isto posto, pode-se dizer que estão muito próximas ao segundo modelo descrito por Antezana (2012), contudo também abrem a possibilidade de desenvolvimento do quarto. Por outro lado, descartam, expressamente, serviços fundamentados no primeiro modelo, pois os autores de violência são vistos não como doentes ou pessoas com transtornos de personalidade, e sim como seres inseridos em contextos socioculturais sexistas e machistas que naturalizam tais violências. Algumas intervenções brasileiras, apesar de fundamentações teóricas pautadas em princípios do segundo ou quarto modelo, acabam, no cotidiano dos grupos, se restringindo a aplicação do modelo cognitivo-comportamental (Bernardes; Mayorga, 2017). É a partir disso que discussões sobre a formação de facilitadores se torna tão importante. As Recomendações definem que:

1. A equipe multidisciplinar deverá ter atuação interdisciplinar e ser composta por, no mínimo: 1 coordenador; 1 profissional de Ciências Sociais, Pedagogia, Psicologia e/ou Serviço Social com experiência na condução de grupos e capacitados nas questões de gênero, feminismo $e$ masculinidades; 2 estagiários (Direito, Pedagogia, Psicologia, Ciências Sociais e/ou Serviço Social); 
equipe de apoio técnico (1 auxiliar administrativo, 1 recepcionista); 1 motorista e profissionais de segurança.

2. A equipe deverá participar, ao ingressar no serviço, por um curso de capacitação, com carga horária mínima de 60 horas, nas questões de violência contra as mulheres, gênero e masculinidades (segundo o conteúdo mínimo das capacitações previsto no Termo de Referência do Pacto Nacional de Enfrentamento à Violência contra as Mulheres).

3. A agenda de funcionamento do Centro deve prever reuniões da equipe para estudos de casos, formação e atualização dos profissionais e outros procedimentos que se façam necessários;

4. A prática interdisciplinar é indispensável, devendo orientar-se, prioritariamente, para atividades pedagógicas e educativas com o agressor, a partir de uma abordagem responsabilizante e de uma perspectiva feminista de gênero.

5. Deverá ser realizada avaliação periódica das atividades desenvolvidas pelo serviço, por meio de reuniões de equipe, supervisão técnica e mecanismos de controle social (Brasil, 2008:5).

Em relação à capacitação inicial e formação periódicas, entre os serviços entrevistados no relatório do Instituto Noos, 84,2\% declararam realizá-las (Beiras, 2014). Já o relatório CEPIA (2016) identificou que a maior parte dos profissionais não passou por nenhuma atividade anterior de formação e capacitação para o trabalho com os grupos. Nas entrevistas

[...] se percebe que o conhecimento é buscado individualmente, no desenvolvimento dos trabalhos. Apenas em São Paulo e Belo Horizonte, onde se encontram grupos pioneiros no trabalho com agressores, se identifica também a preocupação com a qualificação acadêmica para o exercício da atividade com homens" (Cepia, 2016:49).

Segundo esse mesmo relatório, a maior parte das iniciativas em capitais são conduzidas pelas equipes multidisciplinares que atendem nos órgãos da justiça - juizados/varas de violência doméstica e familiar ou promotorias especializadas, havendo também, uma parcela de profissionais voluntários e estagiários. Nesses casos, os grupos com homens autores de violência se tornam uma atividade a mais, para a qual poucos profissionais são realmente capacitados para trabalhar (Cepia, 2016).

Além da falta de formação para as diferentes metodologias utilizadas nas intervenções estatais no país, deve se questionar o tipo de formação e sua fundamentação teórica quando existente (Antezana, 2012; Billand, 2016; Amado, 2017). Isso porque é somente a partir da fundamentação teórica da intervenção que é possível refletir sobre a adequação da metodologia ao que se busca alcançar com cada serviço. Nesse sentido, ainda que a diversidade de experiências brasileiras possa ser benéfica no âmbito de adequação da

[...] implementação da Lei às realidades locais, recursos humanos $e$ financeiros disponíveis, $e$ o próprio perfil do público atendido, por outro lado, a padronização conceitual e metodológica é fundamental para garantir que se atinja o fim social previsto na Lei Maria da Penha, de erradicar a violência baseada no gênero (Cepia, 2016:11).

Se, segundo as Recomendações, as intervenções com autores de violência têm como objetivo "provocar a desconstrução e a mudança dos padrões naturalizados de gênero, violência de gênero e de masculinidade hegemônica" (Andrade, 2014:181), não só as capacitações são necessárias, como um constante exercício crítico dos profissionais que facilitam os grupos. Para possibilitar espaços que promovam a reflexão e a desconstrução de gênero nos grupos, quem os facilita precisa se implicar e revisar profundamente suas crenças e práticas cotidianas que reificam desigualdade de gênero e violência (Beiras; Bronz, 2016). E essa implicação e revisão é um processo constante, visto que o trabalho de intervenção é arriscado, "sempre no limite da reprodução dos preconceitos que se pretende combater" (Billand, 2016:123).

Quanto às questões organizacionais, cabe ressaltar que as Recomendações determinam que o serviço

[...] deverá possuir sede própria ou estar vinculado diretamente ao sistema de justiça. Sob nenhuma hipótese, o equipamento poderá funcionar nos serviços especializados de atendimento 
à mulher, tais como: Casas-Abrigo, Centros de Referência, Delegacias Especializadas de Atendimento à Mulher, Defensorias Públicas da Mulher e Núcleos de Gênero dos Ministérios Públicos (Brasil, 2008:4).

O sistema de justiça é entendido em sentido amplo, englobando o Poder Judiciário, Secretarias de Justiça Estadual e/ou Municipal e administração penitenciária (Cepia, 2016). Hoje já se tem documentado iniciativas em Tribunais de Justiça, Fóruns, Centrais de penas e medidas alternativas, Ministério Público, Defensorias, Delegacias, Centros de referência especializados de assistência social (CREAS), serviços de saúde, presídios, ONGs, Universidades, entre outros. Essa diversidade tem levado a discussões sobre qual seria o melhor local para a realização dos serviços. Não é possível, contudo, desvincular essa análise da finalidade dessa política - punição, responsabilização, reflexão e/ou educação.

Independentemente do local onde for desenvolvido, o serviço é previsto como parte das ações de enfrentamento à violência, e como tal, integrante da Rede de Atendimento e de Enfrentamento à violência contra as mulheres, devendo atuar de forma articulada com os demais serviços especializados ${ }^{9}$ e não especializados oferecidos nos âmbitos dos Governos Federal, Estadual/Distrital, Municipal e da sociedade civil. A criação de um atendimento em rede perpassa a ideia de que existe uma rota crítica, que é o caminho que cada mulher percorre na busca de uma resposta do Estado frente a situação de violência. Ela possui diversas portas de entrada, que podem ser serviços de saúde, delegacias, serviços da assistência social, educação, etc. Quando não articuladas, essa trajetória pode se caracterizar por "por idas e vindas, círculos que fazem com que o mesmo caminho seja repetido sem resultar em soluções, levando ao desgaste emocional e à revitimização" (Brasil, 2011:30). Assim, a Rede de atendimento é fundamental para dar conta da complexidade da violência, garantir a integralidade do atendimento, e possibilitar seu enfrentamento.

As Recomendações não preveem tempo de participação ou número de encontros. Em pesquisa latino-americana, Toneli et al. (2010) identificam que a maioria dos serviços de caráter grupal analisados se reúnem de forma semanal por no mínimo um ano. No Brasil, o número de sessões é variável. O relatório do Instituto Noos identificou formatos que previam entre 3 e 20 encontros. Dos 19 serviços analisados, 6 deles não definia um número fixo de encontros. O serviço de Blumenau/SC justifica essa indeterminação pela compreensão de que as pessoas têm necessidades e subjetividades distintas que devem ser respeitadas no desenvolvimento desse tipo de trabalho (Beiras, 2014). Já os serviços analisados pela CEPIA (2016), a maioria ocorre em formato de grupos de 10 a 15 homens, em média, com número de encontros variando de 6 a 19 sessões, semanais ou quinzenais.

O tempo de acompanhamento é uma característica extremamente relevante da metodologia, pois influencia na possibilidade de afetação pela intervenção e, consequentemente, no processo reflexivo dos participantes (Silva; Coelho, 2017; Amado, 2017). Em intervenções muito curtas, corre-se o risco de apropriação instrumental de discursos, sem que nenhum processo de transformação tenha sido iniciado (Cepia, 2016). Existem estudos nacionais que indicam que um trabalho inferior a seis meses será superficial e não contribuirá para o combate da violência (Veloso; Natividade, 2013). Já a literatura internacional "demonstra que o caráter reflexivo do trabalho pode ser alcançado com, no mínimo, 10 encontros" (Beiras; Bronz, 2016:13). Contudo, em grupos com menos de 12 encontros torna-se difícil a inclusão de questões individuais, bem como o aprofundamento dos temas debatidos (Beiras; Bronz, 2016).

Outra discussão relevante se refere à forma de ingresso e vinculação. Os serviços podem ser obrigatórios via decisão judicial, voluntários ou conjugar as duas possibilidades. Nos casos de vinculação obrigatória via determinação judicial, diversas pesquisas ressaltam a resistência inicial

\footnotetext{
9 "Centros de Referência de Atendimento à Mulher; Núcleos de Atendimento à Mulher; Casas-Abrigo; Casas de Acolhimento Provisório; Delegacias Especializadas de Atendimento à Mulher (DEAMs); Núcleos ou Postos de Atendimento à Mulher nas Delegacias Comuns; Polícia Civil e Militar; Instituto Médico Legal; Defensorias da Mulher; Juizados de Violência Doméstica e Familiar; Central de Atendimento à Mulher - Ligue 180; Ouvidorias; Ouvidoria da Mulher da Secretaria de Políticas para as Mulheres; Serviços de Saúde voltados para o atendimento dos casos de violência sexual e doméstica; Posto de Atendimento Humanizado nos Aeroportos" (SPM, 2011:30).
} 
dos participantes (Silva; Coelho, 2017; Santos, 2012). Contudo, essa resistência pode ser vencida a partir da sensibilização e criação de um espaço acolhedor pelos facilitadores.

Alguns serviços conjugam as duas possibilidades, criando potentes espaços de trocas entre participantes compulsórios e espontâneos - como o PPCVDI de Blumenau/SC, do NAFAVD do Distrito Federal, do ISER do Rio de Janeiro, entre outros (Beiras, 2014). Esses serviços recebem tanto a "demanda espontânea de homens que procuram atendimento por estímulo das companheiras, ou porque conheceram o trabalho e sentem que poderiam ser ajudados por ele" (Cepia, 2016:43), quanto homens encaminhados em decorrência de determinação judicial, pela rede de enfrentamento à violência, Conselho Tutelar, entre outros.

Já nos serviços completamente espontâneos, o maior desafio é a não continuidade dos participantes (Lima, 2008, Oliveira, 2012; Santos, 2012; Amado, 2017). Nesses casos, as altas taxas de desistência devem ser levadas em conta na avaliação e investigadas. Pois, pouco se sabe sobre os efeitos que essas intervenções podem ter naqueles que não completaram o ciclo de encontros (Amado, 2017).

A avaliação é um processo de aprendizagem que pode subsidiar pessoas e organizações em escolhas mais consistentes em relação aos rumos das intervenções (Minayo, 2005). A inserção de um processo de monitoramento $e$ avaliação do trabalho em paralelo à sua realização, não é somente importante para a equipe, como também para os participantes que poderão refletir sobre os efeitos e a relevância do grupo para a própria vida (Beiras; Bronz, 2016). Contudo, é nesse âmbito que se encontra uma das principais lacunas dos serviços, já que os processos avaliativos ainda são bastante rudimentares, quando não inexistentes (Toneli et al., 2010; Antezana, 2012; Cepia, 2016; Amado, 2017). O Relatório da CEPIA (2016:61) ressalta que

[...] a ausência de instrumentos para registro dos atendimentos e qualquer forma de avaliação sobre esses serviços faz com que as respostas sejam produzidas e reproduzidas sem que haja resultados para análise dos efeitos alcançados. Nesse cenário, não é possível saber quanto e como essas iniciativas analisadas contribuem para a mudança esperada ou o que seria necessário para aprimorar estas experiências e torná-las mais exitosas. É fundamental que os profissionais que elaboram esses projetos e buscam sua implementação sejam convidados a refletir sobre os resultados que desejam alcançar e se os meios utilizados estão sendo compatíveis com esses propósitos.

Alguns serviços se utilizam de índices oficiais de reincidência, nos quais é medida a diminuição ou ausência de novas denúncias como indicador de resultado, que pode ser explicada, entre outros motivos: pela falta de confiança na polícia como uma instituição que possa proteger mulheres; pelo rechaço e/ou medo do encarceramento de seus companheiros; pela revitimização operada pela falta de serviços de acolhimento e/ou tratamento recebido em denúncias anteriores. Todas essas explicações precisam ser analisadas e compreendidas através da interseccionalidade (Akotirene, 2019), levando em consideração os sistemas de opressão que estruturam nosso país, e seus reflexos nas instituições. Nesse sentido, esse indicador é bastante frágil e limitado, tanto por reduzir a violência à crimes passíveis de denúncia, quanto por desconsiderar a subnotificação $e$ outras possibilidades "que não a mudança de comportamento dos participantes da intervenção para não ter havido novas denúncias contra eles" (Soares, 2018:29).

Alguns serviços se utilizam de questionários aplicados aos participantes antes e depois (ou no último encontro) do ciclo de intervenção (Mistura; Andrade, 2017; Soares, 2019). São raras as iniciativas que mantém contato com os participantes após o período de intervenção, o que inviabiliza avaliação sobre os alcances das modificações ocorridas (Amado, 2017). As Recomendações de 2008 definem que:

[...] ainda que as intervenções sejam produzidas por diferentes metodologias é preciso definir indicadores de processo e de resultado que permita ao Estado e a sociedade civil acompanhar os resultados e efeitos do serviço, da rede e da política no que se refere ao enfrentamento da violência contra a mulher (Brasil, 2008:5). 
Desse modo, a avaliação é parte integrante da intervenção, e "deve estar baseada em informações qualitativas e quantitativas, coletadas a partir da mulher, do homem e dos demais atores envolvidos" (Brasil, 2008:5). Mesmo com essa diretriz de 2008, as mulheres não têm sido ouvidas nos incipientes processos avaliativos. O único serviço encontrado que faz menção às mulheres nos processos avaliativos é o Projeto Dialogar desenvolvido pela Delegacia Especializada de Atendimento à Mulher (DEAM) do Estado de Minas Gerais, que realiza contatos telefônicos com as ex-companheiras dos participantes dos grupos (Bernardes; Mayorga, 2017). Ou seja, pouco se fala com as mulheres e mais uma vez parece que sua voz não tem importância para o desenvolvimento de políticas que impactam diretamente a sua vida.

É necessário pensar os serviços para autores de violência junto com as mulheres que decidem permanecer em suas relações, e, nos casos de separação, com as novas parceiras desses homens, considerando sempre as diferenças históricas, culturais e sociais entre mulheres. Pois, uma compreensão adequada da situação de violência deve levar em conta os significados prevalentes no grupo cultural de referência dos envolvidos (Toneli; Beiras; Reid, 2017). Se não, pode-se recair, novamente, em práticas de silenciamento maciço das vozes de mulheres e outros sujeitos impactados pela violência de gênero (Debert; Gregori, 2008).

\section{Considerações finais}

Passaram-se quase trinta anos da criação das primeiras intervenções no país, desenvolvidas em um contexto de grande movimentação política, em que a maioria das políticas de enfrentamento à violência doméstica e familiar era de iniciativa da sociedade civil organizada. A Lei Maria da Penha, além de introduzi-las no ordenamento jurídico, impulsionou pesquisas e o desenvolvimento das intervenções com autores de violência por órgãos governamentais, alcançando todas as regiões do país. Apesar disso não é possível afirmar que estão suficientemente difundidas, uma vez que essas políticas estão presentes em menos de $3 \%$ dos municípios brasileiros.

No âmbito dos serviços implementados, eles sofrem com a falta de continuidade nas trocas de gestão pública; com a resistência de operadores do Direito em encaminhar autores de violência; com a insuficiência de recursos financeiros e humanos para seu desenvolvimento, manutenção $e$ avaliação; com a falta de integração com a rede de enfrentamento $e$ atendimento à violência doméstica e familiar; e com a incorporação superficial de perspectivas feministas de gênero.

Incorporar uma perspectiva feminista de gênero tem como pressuposto "a ressignificação da história, da sociedade, da cultura e da política a partir das mulheres e com as mulheres" (Lagarde, 1996:13). Ou seja, compreender homens e mulheres não como seres dados, eternos e imutáveis, mas sim como sujeitos históricos, construídos socialmente. Perspectivas feministas, principalmente as desenvolvidas por intelectuais negras, nos permitem olhar para as relações de poder $e$ compreender as desigualdades sociais como reflexos da interconexão de sistemas de opressão de gênero, raça/etnia, classe, sexualidade, geração, entre outros (Collins, 2015; Akotirene, 2019). Assim, para potencializar as possibilidades de transformações operadas pelas intervenções, é necessário que as políticas existentes cumpram as recomendações da SPM de capacitações $e$ formação periódicas, ampliando-as para operadores de direito e servidores públicos que atuem em toda rede de enfrentamento à violência. Essas formações periódicas amplas poderiam, inclusive, fomentar a articulação da rede em âmbito local, extremamente necessária tanto no âmbito de um atendimento integral às mulheres em situação de violência, quanto para que não se perca de vista que esses serviços visam o questionamento das relações de poder e de opressão que permitem a naturalização da violência enquanto prática social de controle de corpos de mulheres.

As intervenções com autores de violência, principalmente aquelas em formato de grupos reflexivos, são espaços dialógicos que possibilitam que os participantes sintam a necessidade interna de superar seus problemas, o que Adriano Beiras (2012:294) chama de "implicação subjetiva para a mudança". Essa implicação importa porque a responsabilização é um processo interno, não algo externo que possa ser ensinado, mas sim facilitado através da reflexão compartilhada (Acosta, 2013). A responsabilização visa implicar os sujeitos nas escolhas feitas e assim quebrar discursos justificadores e naturalizantes sobre as violências praticadas, problematizando a estrutura social de desigualdades e privilégios e posicionando os sujeitos dentro delas como responsáveis pela 
manutenção ou transformação dessa estrutura hierárquica, no seu cotidiano e em suas relações (Lattanzio; Barbosa, 2013). Desta forma, os grupos funcionam como impulsionadores de responsabilização perante a violência, mas seus efeitos não são os mesmos para todos os participantes (Silva; Coelho, 2017; Soares, 2018). Esses efeitos têm sido bastante discutidos em pesquisas, contudo, para que cada serviço consiga potencializar suas ações, é necessário que sejam instituídos processos de monitoramento internos como parte integrante da intervenção, ampliando a compreensão do contexto social e cultural de seus participantes, assim como das resistências iniciais, e das dificuldades experienciadas pelos participantes e facilitadores ao longo do processo. Essas informações, conjugadas com avaliações ao final do acompanhamento, possibilitam que os profissionais implementadores reflitam sobre a compatibilidade entre os objetivos do serviço, a metodologia e os resultados obtidos. Possibilitando assim aprimorar estas experiências e alcançar mais participantes.

Como prevê as recomendações, as avaliações precisam ser amplas, baseando-se na escuta de homens, mulheres e demais atores envolvidos, não perdendo de vista que se os objetivos dos serviços são a prevenção de novas violências, sua aliança deve se dar com as mulheres. Para tanto, é necessário pensar os serviços para autores de violência junto das mulheres em situação de violência, considerando suas intersecções de raça/etnia, classe, sexualidade, geração, capacidade, entre outras, de forma a ampliar suas potencialidades de enfrentamento às violências atuais $e$ futuras.

\section{Referências bibliográficas}

ACOSTA, Fernando. Entrevista com Fernando Acosta (com a participação de Alan Bronz) [Entrevista concedida a Milena do Carmo dos Santos]. In: LEITE, Fabiana; LOPES, Paulo Victor Leite (org.). Atendimento a homens autores de violência doméstica: desafios à política pública. Rio de janeiro, ISER, 2013, pp.87-105.

ACOSTA, Fernando et al. Conversas homem a homem: grupo reflexivo de gênero - metodologia. Rio de Janeiro, Instituto Noos, 2004.

AGUIAR, Luiz Henrique Machado de. Follow-up de uma intervenção com homens autores de violência conjugal. Dissertação (Mestrado em Psicologia Clínica e Cultura), Universidade de Brasília, 2009.

AKOTIRENE, Carla. Interseccionalidade. São Paulo, Pólen Produção Editorial Ltda, 2019.

AMADO, Roberto Marinho. O que fazer com os homens autores de violência contra as mulheres? Uma análise sobre serviços destinados aos homens processados pela Lei Maria da Penha. In: BEIRAS, Adriano; NASCIMENTO, Marcos (org.). Homens e violência contra mulheres. Pesquisas e intervenções no contexto brasileiro. Rio de Janeiro, Instituto Noos, 2017, pp.216-238.

ANDRADE, Leandro Feitosa. Grupos de homens e homens em grupos: novas dimensões e condições para as masculinidades. In: BLAY, Eva Alterman (org.). Feminismos e masculinidades. Novos caminhos para enfrentar a violência contra a mulher. São Paulo, Cultura Acadêmica, 2014, pp.173-210.

ANDRADE, Vera Regina Pereira de. Criminologia e feminismo: da mulher como vítima à mulher como sujeito de construção da cidadania. Seqüência: Estudos Jurídicos e Políticos, Florianópolis, jan. 1997, v. 18, n. 35, pp.42-49.

ANTEZANA, Álvaro Ponce. Intervenção com homens que praticam violência contra seus cônjuges: reformulações teórico-conceituais para uma proposta de intervenção construtivista-narrativista com perspectiva de gênero. Revista Nova Perspectiva Sistêmica, Rio de Janeiro, v. 21, n. 42, abr. 2012, pp.925.

BATITUCCI, Eduardo Cerqueira et alii. A justiça informal em linha de montagem. Estudo de caso da dinâmica de atuação do JECrim de Belo Horizonte. Civitas - Revista de Ciências Sociais, Porto Alegre, v. 10, n. 2, maio-ago 2010, pp.245-269.

BEIRAS, Adriano. Grupos de homens autores de violência - possibilidades de intervenções diante das recomendações propostas na lei Maria da Penha. In: ROVINSKI, S.; CRUZ, R. (org.). Psicologia jurídica: perspectivas teóricas e processos de intervenção. São Paulo, Vetor Editora Psico-Pedagógica, 2009, pp.129-144. 
BEIRAS, Adriano. La (de)construcción de subjetividades en un grupo terapéutico para hombres autores de violencia en sus relaciones afectivas. Tesis (Doctorado en Psicología Social), Universidad Autónoma de Barcelona, España, 2012.

BEIRAS, Adriano. Relatório Mapeamento de Serviços de atenção grupal a homens autores de violência contra mulheres no contexto brasileiro. Rio de Janeiro, Instituto Noos, Instituto Promundo, 2014.

BEIRAS, Adriano; BRONZ, Alan. Metodologia de grupos reflexivos de gênero. Rio de Janeiro, Instituto Noos, 2016.

BEIRAS, Adriano; NASCIMENTO, Marcos; INCROCCI, Caio. Programas de atenção a homens autores de violência contra as mulheres: um panorama das intervenções no Brasil. Saúde e Sociedade, v. 28, n. 1, 2019, pp.262-274.

BENEVIDES, Bruna; NOGUEIRA, Sayonara Naider Bonfim (org.). Dossiê dos assassinatos e da violência contra travestis e transexuais no Brasil em 2019. São Paulo, Expressão Popular, ANTRA, IBTE, 2020 [https://antrabrasil.files.wordpress.com/2020/01/dossic3aa-dos-assassinatos-e-da-violc3aancia-contrapessoas-trans-em-2019.pdf - acesso em jan. 2020].

BERNARDES, João Paulo; MAYORGA, Claudia. Um estudo sobre intervenções junto a homens autores de violência doméstica contra mulheres. Revista de Psicologia, 26(1), 2017, pp.1-15.

BILLAND, Jan Stanislas Joaquim. Como dialogar com homens autores de violência contra mulheres? Etnografia de um grupo reflexivo. Tese (Doutorado em Medicina Preventiva), Universidade de São Paulo, São Paulo, 2016.

BRASIL. Lei n. 11.340, de 7 de agosto de 2006. Planalto. Cria mecanismos para coibir a violência doméstica e familiar contra a mulher, nos termos do $\$ 8^{\circ}$ do art. 226 da Constituição Federal, da Convenção sobre a Eliminação de Todas as Formas de Discriminação contra as Mulheres e da Convenção Interamericana para Prevenir, Punir e Erradicar a Violência contra a Mulher; dispõe sobre a criação dos Juizados de Violência Doméstica e Familiar contra a Mulher; altera o Código de Processo Penal, o Código Penal e a Lei de Execução Penal; e dá outras providências. Brasília, DF [http://www.planalto.gov.br/ccivil_03/_ato2004-2006/2006/lei/111340.htm - acesso em: 20 jan 2018].

BRASIL. Presidência da República. Secretaria Especial de Políticas para as Mulheres. Proposta para Implementação dos Serviços de Responsabilização e Educação dos Agressores. Brasília, 2008.

BRASIL. Secretaria de Políticas para Mulheres. Política Nacional de Enfrentamento à Violência Contra as Mulheres. 2011 [https://www12.senado.leg.br/institucional/omv/entenda-a-violencia/pdfs/politica-nacionalde-enfrentamento-a-violencia-contra-as-mulheres - acesso em: 10 ago 2020].

CAMPOS, Carmen Hein de. The Joint Parliamentary Committee of Enquiry and the Implementation of the Maria da Penha Law. Revista Estudos Feministas, v. 23,n. 2, Florianópolis, ago. 2015, pp.519-531.

CEPIA - CIDADANIA, ESTUDO, PESQUISA, INFORMAÇÃO E AÇÃO. Relatório de Pesquisa Violência contra as mulheres os serviços de responsabilização dos homens autores de violência. Rio de Janeiro, 2016.

COLLINS, Patricia Hill. Em direção a uma nova visão: raça, classe e gênero como categorias de análise e conexão. In: MORENO, Renata (org.). Reflexões e práticas de transformação feminista. São Paulo, SOF, 2015, pp.13-42.

DEBERT, Guita Grin; GREGORI, Maria Filomena. Violência e gênero: novas propostas, velhos dilemas. Revista Brasileira de Ciências Sociais, São Paulo, v. 23, n. 66, 2008, p. 165-185.

GONÇALVES, João Paulo Bernardes. As intervenções com homens autores de violência doméstica contra as mulheres ante suas bases teórico-metodológicas e perspectivas políticas: As experiências no estado de Minas Gerais. Dissertação (Mestrado em Psicologia), Universidade Federal de Minas Gerais, Belo Horizonte, 2015.

HÍJAR, Martha; VALDÉZ, Rosario (ed.). Programa de reeducación para víctimas y agresores de violencia de pareja: manual para responsables de programa. Cuernavaca, Instituto Nacional de Salud Pública, 2010.

IBGE. Instituto Brasileiro de Geografia e Estatística. Coordenação de População e Indicadores Sociais. Pesquisa de Informações Básicas Municipais. Perfil dos municípios brasileiros 2018. Rio de Janeiro, IBGE, 2019. 
LAGARDE, Marcela. Género y feminismo - desarrollo humano y democracia. Madrid, Horas \& horas, 1996.

LATTANZIO, Felippe Figueiredo; BARBOSA, Rebeca Rohlfs. Grupos de gênero nas intervenções com as violências masculinas: paradoxos da identidade, responsabilização e vias de abertura. In: LEITE, Fabiana; LOPES, Paulo Vitor Leite. Atendimento a homens autores de violência. Rio de Janeiro, ISER, 2013, pp.87-106.

LIMA, Daniel Costa. Homens autores de violência doméstica e familiar contra a mulher: desafios e possibilidades. Dissertação (Mestrado em Saúde Pública), Universidade Federal de Santa Catarina, Florianópolis, 2008.

LIMA, Daniel Costa; BUCHELE, Fátima. Revisão crítica sobre o atendimento a homens autores de violência doméstica e familiar contra as mulheres. Physis, v.21, n.2, 2011 pp.721-743.

LISBOA, Teresa Kleba. Violência de gênero ou feminicídio? Leis sobre violência e propostas de políticas públicas no Brasil e no México. In: RIAL, Carmen; PEDRO, Joana Maria; AREND, Silvia Maria Favero (org.). Diversidades: dimensões de gênero e sexualidade. Florianópolis, Editora Mulheres, 2010, pp.61-80.

LISBOA, Teresa Kleba. Violência de gênero, políticas públicas para o seu enfrentamento e o papel do Serviço Social. Temporalis, ano 14, n. 27, Brasília, DF, jan./jun. 2014, pp.33-56.

MARTINS, Daniel Fauth. Desarmando Masculinidades: os grupos para autores de violência doméstica no Paraná. Dissertação (Mestrado em Direito), Universidade Federal do Paraná, Curitiba, 2020.

MINAYO, Maria Cecilia de Souza. Mudança: conceito-chave para intervenções sociais e para avaliação de programas. In: MINAYO, Maria Cecilia de Souza et al. (org.). Avaliação por triangulação de métodos. Abordagem de Programas Sociais. Rio de Janeiro, Editora Fiocruz, 2005, pp. 53-70.

MISTURA, Tales; ANDRADE, Leandro Feitosa. Mensagem aos outros homens: a contribuição de exparticipantes do grupo reflexivo de homens. In: BEIRAS, Adriano; NASCIMENTO, Marcos (org.). Homens e violência contra mulheres. Pesquisas e intervenções no contexto brasileiro. Rio de Janeiro, Instituto Noos, 2017, pp.239-270.

MONTEIRO, Andrés; BONINO, Luis. Criterios de calidad para intervenciones con varones que ejercen violencia en la pareja (HEVPA). Cuadernos para el debate - Grupo 25, Madrid, 2006, pp.1-33.

MUSZKAT, Susana. Violência e masculinidade: uma contribuição psicanalítica aos estudos das relações de gênero. Dissertação (Mestrado em Psicologia Social), Universidade de São Paulo, São Paulo, 2006.

NOTHAFT, Raíssa Jeanine. Experiência de mulheres no enfrentamento à violência doméstica e familiar e suas relações com os serviços para autores de violência. Tese (Doutorado em Ciências Humanas), Universidade Federal de Santa Catarina, Florianópolis, 2020.

NOTHAFT, Raíssa Jeanine. Intervenções com autores de violência doméstica e familiar na produção acadêmica nacional (2006-2015). Dissertação (Mestrado em Ciência Política), Universidade Federal do Rio Grande do Sul, Porto Alegre, 2016.

OLIVEIRA, Anderson Eduardo Carvalho de. Atendimento a homens autores de violência contra a mulher: lacunas, desafios e perspectivas. Dissertação (Mestrado em Estudos sobre mulheres, gênero e feminismo), Universidade Federal da Bahia, Salvador, 2012.

PASINATO, Wânia. Oito anos de Lei Maria da Penha: Entre avanços, obstáculos e desafios. Revista Estudos Feministas, v. 23, n. 2, Florianópolis, 2015, pp.533-545.

PASINATO, Wânia. Delegacias de Defesa da Mulher e Juizados Especiais Criminais: contribuições para a consolidação de uma cidadania de gênero. Revista Brasileira de Ciências Criminais, n. 40, 2002, pp.282295.

PAZO, Concepción Gandara. Novos frascos, velhas fragrâncias: a institucionalização da Lei Maria da Penha em uma cidade fluminense. Tese (Doutorado em Saúde Coletiva), Universidade do Estado do Rio de Janeiro, Rio de Janeiro,2013.

PRÁ, Jussara Reis. Metodologias feministas, gênero, políticas públicas e o monitoramento da Lei Maria da Penha. In: RIAL, Carmen; PEDRO, Joana Maria; AREND, Silvia Maria Fávero (org.). Diversidades: dimensões de gênero e sexualidade. Florianópolis, Editora Mulheres, 2010, pp.81-101.

SANTOS, Cecília MacDowell. Da delegacia da mulher à Lei Maria da Penha: Absorção/tradução das demandas feministas pelo Estado. Revista Crítica de Ciências Sociais, 89, 2010, pp.153-170. 
SANTOS, Cecília MacDowell; PASINATO, Wânia. Violência contra as Mulheres e Violência de Gênero: Notas sobre Estudos Feministas no Brasil. Revista Estudios Interdisciplinarios de America Latina y El Caribe. Israel, v.16, n. 1, 2005.

SANTOS, Milena do Carmo Cunha dos. Eu ser um homem feminino não fere meu lado masculino: percepções e socializações nos grupos reflexivos de gênero para homens. Dissertação (Mestrado em Sociologia), Universidade Federal do Rio Grande do Sul, Porto Alegre, 2012.

SEGATO, Rita Laura. Las Estructuras Elementales de la Violencia. Buenos Aires, Prometeo, 2003.

SILVA, Anne Caroline Luz Grüdtner da; COELHO, Elza Berger Salema. Acompanhamento de homens autores de violência contra a parceira íntima: um estudo de caso. In: BEIRAS, Adriano; NASCIMENTO, Marcos (org.). Homens e violência contra mulheres. Pesquisas e intervenções no contexto brasileiro. Rio de Janeiro, Instituto Noos, 2017, pp.196-215.

SINHORETTO, Jacqueline; TONCHE, Juliana. Justiça restaurativa e os direitos das mulheres. Anais $19^{\circ}$ Congresso Brasileiro de Sociologia, 2019, pp.1-17.

SOARES, Bárbara Musumeci. Os homens do século XXI. Apresentação. In: ACOSTA, Fernando et. al. Conversas homem a homem: grupo reflexivo de gênero - metodologia. Rio de Janeiro, Instituto Noos, 2004, pp.7-12.

SOARES, Bárbara Musumeci. A conflitualidade conjugal e o paradigma da violência contra a mulher. Dilemas: Revista de Estudos de Conflito e Controle Social. v. 5, n. 2, abr/mai/jun 2012, pp.191-210.

SOARES, Bárbara Musumeci; ACOSTA, Fernando. Documento base para a elaboração de parâmetros técnicos para os serviços de educação e responsabilização de homens autores de violência doméstica contra mulheres. Rio de Janeiro, Iser, 2012.

SOARES, Cecília Teixeira. Grupos reflexivos para autores de violência contra a mulher: Isso funciona? Tese (Doutorado em Psicologia), Universidade Federal do Rio de Janeiro, Rio de Janeiro, 2018.

TONELI, Maria Juracy Filgueiras. Violência Sexual e Saúde Mental: análise dos programas de atendimento a homens autores de violência sexual. Relatório Final de Pesquisa. Florianópolis, Núcleo de Pesquisa Margens: Modos de Vida, Família e Relações de Gênero, 2007.

TONELI, Maria Juracy Filgueiras; BEIRAS, Adriano; RIED, Juliana. Homens autores de violência contra mulheres: políticas públicas, desafios e intervenções possíveis na América Latina e Portugal. Revista de Ciências HUMANAS, Florianópolis, v. 51, n. 1, jan-jun 2017, pp.174-193.

VELOSO, Flávia Gotelip Correia; NATIVIDADE, Cláudia. Metodologias de abordagem dos homens autores de violência contra as mulheres. In: LEITE, Fabiana; LOPES, Paulo Victor Leite (org.). Atendimento a homens autores de violência doméstica: desafios à política pública. Rio de janeiro, ISER, 2013, pp.45-64.

WWP - WORK WITH PERPETRATORS OF DOMESTIC VIOLENCE IN EUROPE. Guidelines to develop standards for programmes working with male perpetrators of domestic violence. Berlin, 2008. 